\title{
Quality of life and its relation with treatment compliance among schizophrenic patients
}

\author{
Sharbat M. Mohamed ${ }^{1}$, Yasser M. ElSerogy ${ }^{2}$, Nadia A. Abd El-Hameed ${ }^{3}$ \& Azaa M. Abd El-Aziz ${ }^{4}$. \\ ${ }^{1}$. Demonstrator of Psychiatric \& Mental Health Nursing, Faculty of Nursing, Assiut University, Egypt. \\ 2. Professor of Neurology and Psychiatry, Faculty of Medicine- Assiut University, Egypt. \\ 3. Assistant Professor of Psychiatric \& Mental Health Nursing, Faculty of Nursing, Assiut University, Egypt. \\ ${ }^{4 .}$ Lecturer of Psychiatric \& Mental Health Nursing, Faculty of Nursing, Assiut University, Egypt.
}

\begin{abstract}
Quality of life (QoL) is often severely impaired in people with schizophrenia, and compliance to antipsychotic medication has been consistently found to be low in these people. Aim of the study to assess quality of life and its relation with treatment compliance among schizophrenic patients. Subjects \& Method: A descriptive correlational research design was used in this study. Purposive sample was utilized, consisting of 110 patients who have schizophrenia and accepted to share in this study. Tools of the study include personal data, World Health organization Quality of Life Scale and Medication Adherence Rating Scale. Results: The majority of schizophrenic patients had fair level of quality of life and more than half of them are non-adherent with medication. A highly statistically significant difference was found between quality of life and medication adherence. The study Concluded that the majority of schizophrenic patients had fair level of quality of life and a highly statistically significant relation was found between quality of life and medication adherence $(\mathrm{P}=0.012)$. Recommendation: Further studies are needed to investigate non compliance factors on larger sample size in different settings and different tools.
\end{abstract}

\section{Keywords: Quality of life, Treatment compliance \& Schizophrenia.}

\section{Introduction}

Schizophrenia is a serious mental disorder in which the patient experiences distorted perception of reality and disturbances in thinking, behavior, emotions and motivation (Atadokht et al., 2019). In a majority of people, schizophrenia is associated with functional impairment, including poor occupational attainment (Whiteford et al., 2015). Understanding the relationship between the different domains of symptoms and functioning with QoL are important because interventions that focus on psychotic symptoms or functioning alone may fail to improve subjective QoL to the same level (Tan et al., 2019).

The quality of life (QoL) of patients with mental disorders are emphasized in a consumer-oriented and holistic view of health care (Lim \& Lee, 2018). Schizophrenia has long courses, a high tendency to relapse, and adverse impacts on multiple dimensions of functioning. Assessment the impact of schizophrenia on QoL is important in deciding how aggressively the disorders should be treated and for how long measuring outcomes, assessing the health needs of patients, and allocating resources (Aish, 2013). In particular, during long-term therapies subjective perception of general wellness and quality of life are clear factors influencing and maintaining adherence to treatment consequently a significant role has been assigned recently to the notion of subjective well-being and quality of life even in patients submitted to psychotropic medications (Niolu et al., 2015). Adherence generally means the range to which a person's behavior, in terms of taking drugs, following diets and achieving life-style changes, go to for follow-up etc., concurs with medical and health guidance (Chandra et al., 2014).

However, there are hints of indirect relationships between adherence and QoL in people with schizophrenia, e.g. via unwanted side effects, level of functioning, or attitude toward medication (McIlroy, 2018).

Adverse effects of medication are common in treating patients with schizophrenia. Subjective QoL are negatively influenced by the side effects of treatment in schizophrenic patients (de Araújo et al., 2014). Also, compliance rates are normally greater among patients with acute conditions, as matched with those with chronic conditions; persistence among patients with chronic conditions are inopportunely low, falling most intensely after the first 6 months of therapy (Sridhar et al., 2017).

\section{Significance of the study}

Schizophrenia is the fourth leading cause of disability in the developed countries, imposing enormous burdens on the patients, families, and society (Yin et al., 2017). A review of the English literature reported compliance rates of $60-85 \%$ in schizophrenics during the first month of treatment, with only $50 \%$ at 6 months (Sendt et al., 2015).Also, in Egypt, noncompliance increased to three quarters in patients with schizophrenia (Kenfe et al., 2013). 
Where non - compliance with treatment leads to increasing the number of hospital readmission and go to the emergency department (Martin et al., 2018). Treatment adherence is a main determinant of the attainment of pharmacotherapy in schizophrenic patients and can have an influence on their quality of life. So, the present study will help nursing and medical researcher to advance their knowledge regarding treatment adherence and quality of life in schizophrenic patients.

\section{Aim of the study:}

The current study aimed to assess quality of life and its relation with treatment compliance among schizophrenic patients.

\section{Research Questions:}

What extent the relationships between the quality of life and compliance of treatment among schizophrenic patient?

\section{Subjects \& Methods}

Research design: A descriptive correlational research design was used in the study.

Study setting: The study was conducted at outpatient clinic including monthly treatment patients at the neuropsychiatric hospital of Assiut university is the biggest hospital in Upper Egypt provides services for Assiut city and most of the neighboring governorates (Assiut, Sohage, Qena and Aswan). The hospital contains 10 floors for psychiatric departments, it start from the ground floor which includes neurology, neurosurgry, and psychiatric clinics, in the first floor, psychiatric and neurology emergency male and female. The second floor includes female inpatient psychiatric unit, the third floor includes male inpatient psychiatric unit, until the fourth floor includes addiction department. The patient follow up will be done in out -patient clinics.

Study subjects: Non probability (purposive) sample was used. Total sample included 110 patients (50 male \& 60 female).

\section{Inclusion criteria}

Schizophrenic patients aged between 18 to 60 years; diagnosed with schizophrenia spectrum disorders according to DSM- 5 and accepted to participate in the study.

\section{Exclusion criteria}

Patients have mental retardation, neurological or physical illness and who have inability or refuse to share in the study.

Tools of data collection: Each participant was evaluated through the following tools:

1. Demographic and clinical data sheet: This tool was developed by the researcher. It includes age, sex, educational level, marital status, residence, occupation, duration of illness, number of admission, live at home.
2. World Health Organization Quality of Life scale (WHOQOL): This tool was developed by (WHO, 1998). It contains 54 questions over 5 broad domains of QoL. Within each domain several sub domains (facets) of QoL summarize that particular domain of QoL. The 5 main domains are: Physical health domain (7 items); psychological domain (4 items); social relationships domain (3 items); environment domain ( 3 items) and perceived quality of life domain (one item). The initial reliability analyses showed a correlation coefficient of more than 0.40.8 . The validity of the tool ranged from $r=0.244$ and 0.676. Three points likert scale was adopted, which range from never which mean low QoL and assigned (1). Moderately which mean moderate QoL and assigned (2). Much which mean high QoL, and assigned (3). Each facet comprised 3 questions, the score for every facet ranged between 3 to 9.The overall score starts from 54-162 points, and it is interpreted into three categories: Low QoL if patient have (5489scores), fair QoL if patient have (90-126scores) and high QoL if patient have (127-162scores).

3. Medication Adherence Rating Scale (MARS): The MARS developed by (Thompson et al., 2000) contains 10 items self-reporting multidimensional instrument describing three dimension: medication adherence behavior(items1- 4), attitude toward taking medication (items5-8), and negative side effects and attitude to psychotropic medication (items 910) . each question has" yes" or "no" response. Total scores on the MARS rang between 0 to 10 , with a higher score indicating better medication adherence. This scale was modified and translated into Arabic language by the researcher and checked for content validity which was done by juries from 5 experts' psychiatric medicine and nursing. Based on juries' opinion; reliability test was done to the modified scale by using cronbach Alpha and the reliability of the tool was $r=0.786$.

Pilot study: A pilot study was conducted on first 11 patients of the sample. The purpose of the pilot study was to detect any particular problem in the statements clarity, feasibility, and applicability of the tools. No change was done in the assessment sheet, so the patients selected for the pilot study were included in the main study.

Filed work: Data were collected for a period of a months from (Feb to Oct .2020), 2 days per week 4 hours from 9 am to $1 \mathrm{pm}$. The prolonged period of data collection was due to the closure of the out patients clinics from 26|3|2020 till 10|8|2020 because of spread of the Coronavirus. The interviewer selected patients who achieved the criteria. The 
purpose and nature of the study was described to each participant, who approved sharing in the study, oral informed agreement was took from them and subjects were assured about concealment and privacy, the data will be used only for the purpose of research. Each participant was individually interviewed in the waiting area of the outpatient clinics. The tools were filled and completed in a one session. The average time taken for completing each questionnaire was around 30-40 minutes.

\section{Ethical consideration}

1. Research proposal was approved from ethical committee in the faculty of nursing.

2. The study followed common ethical principles in research.

3. There is no risk for study subjects during application of the research.

4. Oral consent was obtained from patient and or informed family member that are willing to participate in the study after explaining purpose of the study.
5. Patients have the right to refuse to participate and/or withdraw from the study at any time.

6. The privacy was considered during collection of data.

7. Confidentiality of obtained data was maintained and ensured for every studied sample before starting data collection

\section{Statistical design}

The data were tested for normality using the Anderson-Darling test and for homogeneity variances prior to further statistical analysis. Categorical variables were described by number and percent $(\mathrm{N}, \%)$, where continuous variables described by mean and standard deviation (Mean, SD). Chisquare test and fisher exact test used to compare between categorical variables where compare between continuous variables by t-test. A twotailed $\mathbf{p}<\mathbf{0 . 0 5}$ was considered statistically significant. Pearson Correlation used for the Association between scores. All analyses were performed with the IBM SPSS 20.0 software.

\section{Results}

Table (1): Distribution of demographic and clinical characteristics of the studied patients (n=110):

\begin{tabular}{|c|c|c|}
\hline Demographic and clinical data & No & $\%$ \\
\hline \multicolumn{3}{|l|}{ Age group } \\
\hline From 18 to Less than 30 years & 36 & 32.7 \\
\hline From 30 - 40 years & 32 & 29.1 \\
\hline More than 40 years & 42 & 38.2 \\
\hline Mean \pm SD (range) & \multicolumn{2}{|c|}{$37.92 \pm 11.65(18-60)$} \\
\hline \multicolumn{3}{|l|}{ Gender } \\
\hline Male & 50 & 45.5 \\
\hline Female & 60 & 54.5 \\
\hline \multicolumn{3}{|l|}{ Residence } \\
\hline Rural & 87 & 79.1 \\
\hline Urban & 23 & 20.9 \\
\hline \multicolumn{3}{|l|}{ Live at home } \\
\hline Live Alone & 2 & 1.8 \\
\hline With Family & 97 & 88.2 \\
\hline In an apartment with his family & 11 & 10.0 \\
\hline \multicolumn{3}{|l|}{ Level of education } \\
\hline Illiterate & 55 & 50.0 \\
\hline Primary education & 27 & 24.5 \\
\hline Preparatory education & 3 & 2.7 \\
\hline Secondary education & 21 & 19.1 \\
\hline University education & 4 & 3.6 \\
\hline \multicolumn{3}{|l|}{ Marital Status } \\
\hline Single & 35 & 31.8 \\
\hline Married & 61 & 55.5 \\
\hline Divorced & 13 & 11.8 \\
\hline Widow & 1 & .9 \\
\hline \multicolumn{3}{|l|}{ Occupation } \\
\hline Housewife & 54 & 49.1 \\
\hline Hand work & 24 & 21.8 \\
\hline Not working & 32 & 29.1 \\
\hline Number of admission & & \\
\hline
\end{tabular}




\begin{tabular}{|l|c|c|}
\hline \multicolumn{1}{|c|}{ Demographic and clinical data } & No & \% \\
\hline $1-2$ times & 19 & 17.3 \\
\hline 3 times & 51 & 46.4 \\
\hline More than 3 times & 40 & 36.4 \\
\hline Mean \pm SD(range) & \multicolumn{2}{|c|}{$3.84 \pm 2.05(1-10)$} \\
\hline Duration of illness & \multicolumn{2}{c|}{} \\
\hline From 1-<2 years & 7 & 6.4 \\
\hline From 2 - <5 years & 21 & 19.1 \\
\hline More than 5 years & 82 & 74.5 \\
\hline Mean \pm SD(range) & \multicolumn{2}{|c|}{$11.60 \pm 7.80(1-40)$} \\
\hline
\end{tabular}

Table (2): Relationship between QoL levels and medication adherence among studied patients $(\mathbf{n}=110)$ :

\begin{tabular}{|l|c|c|c|c|c|}
\hline \multirow{2}{*}{ QoL Levels } & \multicolumn{4}{|c|}{ Medication adherence } \\
\cline { 2 - 5 } & \multicolumn{2}{|c|}{ Non adherent(n=69) } & \multicolumn{2}{|c|}{ Adherent(n=41) } & P. value \\
\cline { 2 - 5 } & No. & $\mathbf{\%}$ & No. & \% & \multirow{2}{*}{$0.012 *$} \\
\hline Low & 12 & 17.4 & 0 & 0.0 & \\
\hline Fair & 56 & 81.2 & 39 & 4.9 & \\
\hline high & 1 & 1.4 & 2 & 5.9 \\
\hline
\end{tabular}

Table (3) Levels of QoL among studied patients (n=110):

\begin{tabular}{|l|c|c|}
\hline \multicolumn{1}{|c|}{ QoL Levels } & No & \% \\
\hline Low & 12 & 10.9 \\
\hline Fair & 95 & 86.4 \\
\hline High & 3 & 2.7 \\
\hline Mean \pm SD(range) & \multicolumn{2}{|c|}{$\mathbf{1 0 3 . 0 3} \pm 9.42(84-128)$} \\
\hline
\end{tabular}

Table (4) Distribution of medication adherence among studied patients ( $n=110)$ :

\begin{tabular}{|l|c|c|}
\hline \multicolumn{1}{|c|}{ Medication adherence rating Scale } & No & \% \\
\hline Non adherent & 69 & 62.7 \\
\hline Adherent & 41 & 37.3 \\
\hline Mean \pm SD(Range) & \multicolumn{2}{|c|}{$4.44 \pm 2.86(0-10)$} \\
\hline
\end{tabular}

Table (5) Relationship between medication adherence, demographic and clinical characteristics:

\begin{tabular}{|c|c|c|c|c|c|c|c|}
\hline \multirow{3}{*}{ Demographic and clinical data } & \multicolumn{6}{|c|}{ Medication adherence } & \multirow{3}{*}{ P. value } \\
\hline & \multicolumn{2}{|c|}{$\begin{array}{c}\text { Non } \\
\text { adherent }(n=69)\end{array}$} & \multicolumn{2}{|c|}{$\operatorname{Adherent}(n=41)$} & \multicolumn{2}{|c|}{ Total(n=110) } & \\
\hline & No. & $\%$ & No. & $\%$ & No. & $\%$ & \\
\hline \multicolumn{8}{|l|}{ Age group } \\
\hline From 18 to less than 30 years & 24 & 34.8 & 12 & 29.3 & 36 & 32.7 & \multirow{3}{*}{0.809} \\
\hline from $30-40$ years & 20 & 29.0 & 12 & 29.3 & 32 & 29.1 & \\
\hline More than 40 years & 25 & 36.2 & 17 & 41.5 & 42 & 38.2 & \\
\hline \multicolumn{8}{|l|}{ Gender } \\
\hline Male & 32 & 46.4 & 18 & 43.9 & 50 & 45.5 & \multirow{2}{*}{0.801} \\
\hline Female & 37 & 53.6 & 23 & 56.1 & 60 & 54.5 & \\
\hline \multicolumn{8}{|l|}{ Residence } \\
\hline Rural & 57 & 82.6 & 30 & 73.2 & 87 & 79.1 & \multirow{2}{*}{0.239} \\
\hline Urban & 12 & 17.4 & 11 & 26.8 & 23 & 20.9 & \\
\hline \multicolumn{8}{|l|}{ Lived at home } \\
\hline Live Alone & 1 & 1.4 & 1 & 2.4 & 2 & 1.8 & \multirow{3}{*}{0.931} \\
\hline With Family & 61 & 88.4 & 36 & 87.8 & 97 & 88.2 & \\
\hline In an apartment with his family & 7 & 10.1 & 4 & 9.8 & 11 & 10.0 & \\
\hline Level of education & & & & & & & \\
\hline
\end{tabular}




\begin{tabular}{|c|c|c|c|c|c|c|c|}
\hline \multirow{3}{*}{ Demographic and clinical data } & \multicolumn{6}{|c|}{ Medication adherence } & \multirow{3}{*}{ P. value } \\
\hline & \multicolumn{2}{|c|}{$\begin{array}{c}\text { Non } \\
\text { adherent }(n=69)\end{array}$} & \multicolumn{2}{|c|}{ Adherent $(n=41)$} & \multicolumn{2}{|c|}{ Total(n=110) } & \\
\hline & No. & $\%$ & No. & $\%$ & No. & $\%$ & \\
\hline Illiterate & 31 & 44.9 & 24 & 58.5 & 55 & 50.0 & \\
\hline Primiary education & 21 & 30.4 & 6 & 14.6 & 27 & 24.5 & \\
\hline Preparatory education & 2 & 2.9 & 1 & 2.4 & 3 & 2.7 & 0.423 \\
\hline Secondary education & 13 & 18.8 & 8 & 19.5 & 21 & 19.1 & \\
\hline University education & 2 & 2.9 & 2 & 4.9 & 4 & 3.6 & \\
\hline \multicolumn{8}{|l|}{ Marital Status } \\
\hline Single & 26 & 37.7 & 9 & 22.0 & 35 & 31.8 & \multirow{4}{*}{0.286} \\
\hline Married & 35 & 50.7 & 26 & 63.4 & 61 & 55.5 & \\
\hline Divorced & 7 & 10.1 & 6 & 14.6 & 13 & 11.8 & \\
\hline Widow & 1 & 1.4 & 0 & 0.0 & 1 & 0.9 & \\
\hline \multicolumn{8}{|l|}{ Occupation } \\
\hline Housewife & 34 & 49.3 & 20 & 48.8 & 54 & 49.1 & \multirow{3}{*}{0.855} \\
\hline Hand work & 16 & 23.2 & 8 & 19.5 & 24 & 21.8 & \\
\hline Not working & 19 & 27.5 & 13 & 31.7 & 32 & 29.1 & \\
\hline \multicolumn{8}{|l|}{ Number of admission } \\
\hline $1-2$ times & 13 & 18.8 & 6 & 14.6 & 19 & 17.3 & \multirow{3}{*}{0.823} \\
\hline 3 times & 32 & 46.4 & 19 & 46.3 & 51 & 46.4 & \\
\hline More than 3 times & 24 & 34.8 & 16 & 39.0 & 40 & 36.4 & \\
\hline \multicolumn{8}{|l|}{ Duration of illness } \\
\hline From $1-<2$ years & 5 & 7.2 & 2 & 4.9 & 7 & 6.4 & \multirow{3}{*}{0.770} \\
\hline From $2-<5$ years & 12 & 17.4 & 9 & 22.0 & 21 & 19.1 & \\
\hline More than 5 years & 52 & 75.4 & 30 & 73.2 & 82 & 74.5 & \\
\hline
\end{tabular}

-Chi-square test

Table (6) Relationship between QoL for patients with their demographic and clinical characteristics:

\begin{tabular}{|c|c|c|c|}
\hline \multirow{2}{*}{$\begin{array}{c}\text { Demographic and } \\
\text { clinical data }\end{array}$} & \multicolumn{3}{|c|}{ Mean \pm SD of QoL } \\
\hline & Mean \pm SD & Range & P.value \\
\hline \multicolumn{4}{|l|}{ Age group } \\
\hline From 18 to less than 30 years & $102.86 \pm 10.94$ & $84-127$ & \multirow{3}{*}{0.990} \\
\hline from $30-40$ years & $103.19 \pm 8.2$ & $86-127$ & \\
\hline More than 40 years & $103.05 \pm 9.08$ & $85-128$ & \\
\hline \multicolumn{4}{|l|}{ Gender } \\
\hline Male & $101.96 \pm 10.49$ & $84-128$ & \multirow{2}{*}{0.280} \\
\hline Female & $103.92 \pm 8.4$ & $84-127$ & \\
\hline \multicolumn{4}{|l|}{ Residence } \\
\hline Rural & $102.56 \pm 9.17$ & $84-128$ & \multirow[b]{2}{*}{0.317} \\
\hline Urban & $104.78 \pm 10.33$ & $84-127$ & \\
\hline \multicolumn{4}{|l|}{ Lived at home } \\
\hline Live Alone & $100 \pm 7.07$ & $95-105$ & \multirow{3}{*}{0.650} \\
\hline With Family & $102.84 \pm 9.76$ & $84-128$ & \\
\hline $\begin{array}{l}\text { In an apartment with his } \\
\text { family }\end{array}$ & $105.28 \pm 6.27$ & $97-115$ & \\
\hline \multicolumn{4}{|l|}{ Level of education } \\
\hline Illiterate & $103.15 \pm 7.85$ & $86-117$ & \multirow{5}{*}{0.608} \\
\hline Primiary education & $101.7 \pm 11.69$ & $84-128$ & \\
\hline Preparatory education & $105 \pm 7$ & $100-113$ & \\
\hline Secondary education & $102.76 \pm 10.49$ & $85-127$ & \\
\hline Univeristy education & $111 \pm 8.68$ & $98-116$ & \\
\hline \multicolumn{4}{|l|}{ Marital Status } \\
\hline Single & $103.66 \pm 8.66$ & $84-117$ & \multirow{3}{*}{0.315} \\
\hline Married & $102.77 \pm 9.56$ & $84-128$ & \\
\hline Divorced & $103.85 \pm 10.46$ & $86-115$ & \\
\hline
\end{tabular}




\begin{tabular}{|c|c|c|c|}
\hline \multirow{2}{*}{$\begin{array}{l}\text { Demographic and } \\
\text { clinical data }\end{array}$} & \multicolumn{3}{|c|}{ Mean \pm SD of QoL } \\
\hline & Mean \pm SD & Range & P.value \\
\hline Widow & $86 \pm 0$ & $86-86$ & \\
\hline \multicolumn{4}{|l|}{ Occupation } \\
\hline housewife & $102.91 \pm 8.25$ & $84-127$ & \multirow{3}{*}{0.745} \\
\hline Hand work & $104.25 \pm 9.79$ & $87-128$ & \\
\hline Not working & $102.31 \pm 11.07$ & $84-117$ & \\
\hline \multicolumn{4}{|l|}{ Number of admission } \\
\hline $1-2$ times & $101.79 \pm 8.51$ & $86-117$ & \multirow{3}{*}{0.161} \\
\hline 3 times & $101.71 \pm 10.64$ & $84-127$ & \\
\hline More than 3 times & $105.3 \pm 7.8$ & $94-128$ & \\
\hline \multicolumn{4}{|l|}{ Duration of illness } \\
\hline From $1-<2$ years & $102.57 \pm 8.06$ & $96-117$ & \multirow{3}{*}{0.903} \\
\hline From 2 - <5 years & $103.86 \pm 10.21$ & $86-127$ & \\
\hline More than 5 years & $102.85 \pm 9.41$ & $84-128$ & \\
\hline
\end{tabular}

Table (1): Showed that 110 patients with chronic schizophrenia were enrolled in the study comprised 50 males and 60 females representing $45.5 \%$ and $54.5 \%$ of the sample. Ages ranged from 18 to 60 years. The majority $(79.1 \%)$ of the studied schizophrenic patients were live in rural area, While $20.9 \%$ of them were live in urban area. As regard to level of education $50.0 \%$ of the studied patients were illiterate, While $24.5 \%$ of the studied patients had Primary education. More than half $(55.5 \%)$ of the studied patients were married, While $31.8 \%$ of them were single. Nearly half $(49.1 \%)$ of the studied schizophrenic patients were house wife, While $29.1 \%$ of them not work. Also, most of the patients (88.2\%) live with family at the time of the study.

Table (2): Revealed that there was highly statistically significant relation between QoL levels and medication adherence of the studied schizophrenic patients $(\mathrm{P}=0.012)$.

Table (3): Showed that the most of schizophrenic patients had fair level of QoL (86.4\%) while 10.9\% of them had poor level of QoL and $2.7 \%$ of studied schizophrenic patients had high level of QoL.

Table (4): Indicated that more than half of the studied schizophrenic patients were non adherent with medication $62.7 \%$.While $37.3 \%$ of them were adherent with medication.

Table (5): Represented that there is no statistically significant difference was found between medication adherence, demographic and clinical characteristics.

Table (6): Revealed that there is no statistically significant difference between QoL, demographic and clinical characteristics.

\section{Discussion}

Schizophrenia can be regarded as a "burden on the quality of life". In recent years, quality of life (QoL) has become a central outcome criterion in research on severe mental illness (Karow et al., 2014).Adherence to pharmacological therapy is essential to relieve psychotic symptoms in schizophrenia. The antipsychotic drugs are effective in approximately $70 \%-80 \%$ of the psychiatric patients; however, an estimated half of the individuals who react greatly to medications are noncompliant with their medication regimen (Zipursky, 2014).

Regarding personal characteristics of the studied schizophrenic patients, the current study revealed that, the mean age of the studied patients was $37.92 \pm 11.65$ years respectively which ranged from 18 - 60 years. This age indicates that schizophrenia affects the Quality of life of the individuals and decrease life expectancy among patients. This could be due to schizophrenia as a chronic disability illness that begins in young age groups. This finding are similar with previous studies reported by Elegbede et al., (2019) who found that the mean age of schizophrenic patients was $37.94 \pm 10.20$. Also Ogunnubi et al., (2017) who assessed medication adherence among Nigerians with schizophrenia and correlation between demographic factors and quality of life, finding that the mean age of schizophrenic patients was $38.54 \pm 11$. The current study clarified that, more than half of the studied patients were females, and the number of female were more than males. This finding is consistent with Desalegn et al., (2020) who reported that females preponderance was also seen by their studies. Otherwise this results disagree with (Hayhurst et al., 2014, Adelufosi et al., 2012 \& Adelufosi et al., 2013) who found that more than half of the participant were male. This could be due to the nature of the society and stigma discourages the females to visit the community mental health clinic and hospital. Concerning residence, the most number of the studied patients were from rural area, this may be correlated with distribution of rural and urban people in general population in Assuit governorate where the rural person constitute around $70 \%$ of the population while 
urban is only $30 \%$ Abdullah et al., (2017). Also this finding explained on the basis of people with schizophrenia are more likely to occupy lower socioeconomic position and reside in area characterized by higher social deprivation. The current study showed that more than two third of studied patients $88.2 \%$ were live with their family. This may be due to the patient need supervision to their medication also because most of the patients from rural area where people live in the family home (extended family), this result go in line with finding of Adelufosi et al., (2012) who report that most of respondents $87.9 \%$ lived with other, largely $84.7 \%$ with first- degree relatives. As regard to the educational level, the current study showed that half of the studied patients were illiterate, this results may be due to that schizophrenia affect cognitive function negatively which including executive function, memory, attention, and abstract reasoning have been recognized as core feature of schizophrenia which consequently influence on educational level. This finding is incongruent with the results of ( Effiong \& Umoh, 2015, El-Azzab \& Abu-Salem, 2018) who found that most of the subjects had secondary level of education. According to marital status of the studied patients, the present study reported that more than half of the sample was married $55.5 \%$. This is because most of the patients are from rural area where early marriage is common and the belief that the patient will be cured when he gets married as well as simplicity of requirement and life. This results is consistent with Desalegn et al., (2020) who reported that more than half of the study participants were married $55 \%$. While this results not on the same line with Adelufosi et al., (2012) who found that majority of patients were single. This finding may be related to the stigmatizing nature of the mental illness that prevent most of the schizophrenic patients in the Egyptian society to be married as they considered less than normal people in responsibility. The results revealed that most of the patients was housewife not working, may be due to the disease process and poor social skill of the patients so they did not have a job. Also because the majority of the sample female and illiterate. Regarding clinical characteristic of the studied patients, the current study reported that about half of the studied patients $46.4 \%$ have had three time hospital admissions, a repeated number of admissions shows the chronic nature of the disorder and may be due to non-adherence to medication. Beyond pointing out the chronic nature of this illness, it also reflects the disabling impacts of this illness, given that the continuous admission of these age groups who form a major part of the labour force may hamper them from contributing meaningfully to the growth of their nations. This finding agree with Ogunnubi et al.,
(2017) who reported that almost of the studied patients had three hospital admission on account of schizophrenia. Regarding to duration of illness, three quarters of the studied patients $74.5 \%$ experience schizophrenia more than 5 years. Many factors may hinder disease recognition for patients with long duration and therefore their presentation to a physician. Some of the symptoms may not be easily recognized by the patients, these patients may have already lost insight throughout the long duration of disease due lack of appropriate treatment.

The present study asked the research question; Results of the present study showed a highly statistically significant difference between quality of life and medication adherence $(\mathrm{P}=0.012)$, positive correlation between them, because non- adherence to medication lead to relapse and deterioration of patients psychiatric health also aggravate patients occupational and social functioning and accordingly affect their life quality. These results are similar to (Adelufosi et al., 2012 \& Endriyani et al., 2019) who found a highly significant difference between medication adherence and quality of life. Otherwise this finding disagrees with (Puschner et al., 2006 and Ebrahem \& Alam, 2016) who reported in their study in Menofia university, Egypt no significant difference between medication adherence and quality of life.

According to the quality of life of the studied patients, the current study found that the majority of patients had faire level of QoL. This could be due to the adverse effects of medication may also affect patients cognition and emotion and increase the risk of somatization. The finding is consistent with the results of Ogunnubi et al., (2017) who found that the most of the studied schizophrenic patients had faire level of quality of life.

Regarding medication adherence, the current study reported that more than half of the studied schizophrenic patients were non adherent with medication and more than one third of them were adherent with medication. This finding is congruent with the results of (Amr et al., 2013, Shehu et al., 2019, Lacro et al., 2002,Chaudhari et al., 2017 \& Ogunnubi et al., 2017) they revealed that more than half of the study participants were non adherent to drug treatment. This result may be due to adverse effects of medication, low social support and financial problems because most of patients do not work or could be related to lack of insight among schizophrenic patients.

Concerning relationship between medication adherence, demographic and clinical characteristics of the studied patients, the study found that no statistically significant difference between medication adherence, personal and clinical characteristics, this 
is because there are many factors that may affect the patient's adherence to medication, such as side effects are the most sub dimension that can influence the medication adherence, cost of the drugs, antipsychotic regimen, symptom severity, health care system and lack of insight with the patients and their family, as after the patients are feeling better; they stop taking drugs because they are unaware of the importance of the treatment. These results go in the line with finding of (Adelufosi et al., 2012, Endriyani et al., 2019 \& Amr et al., 2013) who reported that there are no significant differences between medication adherent and demographic variables.

As regard to relationship between quality of life, personal and clinical characteristics for studied schizophrenic patients, the study revealed that no statistically significant difference was found between quality of life domains, personal and clinical characteristics, this may be due to the quality of life is very much affected by disease and treatment, so the more the patient adheres to the treatment, the better the quality of life. Also, social relationship to which the patients feel they can share moments of both happiness and distress with loved ones and sense of trust and safety and being loved affect quality of life. This finding is incongruent with the results of (Caqueo-Urízar et al., 2020,Guedes de Pinho et al., 2018,Xiang et al., 2008 \& Arraras et al., 2018) they reported that there was statistically significant correlation between demographic and clinical factors and different quality of life domains.

\section{Conclusion}

Based on the result of the present study it can be concluded that, highly statistically significant difference between quality of life and medication adherence $(\mathrm{P}=0.012)$. The majority of schizophrenic patients had fair level of QoL and more than half of them were non adherent with medication. In addition, no statistically significant relation was found between medication adherence, demographic and clinical characteristics of the studied patients. Also, there was no statistically significant difference between quality of life domains, demographic and clinical characteristics.

\section{Recommendations}

Based on the current study findings, the following recommendations are suggested:

1- The psychiatric nurse must use the effective strategies for empowering the quality of life and treatment adherence of patients with schizophrenia.
2- Further studies are needed to investigate noncompliance factors on larger sample size in different settings and different tools.

3- Psychoeducation program is essential for schizophrenic patients to improve their treatment adherence.

\section{References}

- Abdullah, S., Ali, E., \& Abd EL-Hameed, N/., (2017): Assessment of Psychological Aspect of Infertile Male (masters thesis).Faculty of Nursing Assuit University.

-Adelufosi, A., Adebowale, T., Abayomi, O., \& Mosanya, J., (2012): Medication adherence and quality of life among Nigerian outpatients with schizophrenia. General hospital psychiatry, 34(1), 72-79.

-Adelufosi, A., Ogunwale, A., Abayomi, O., \& Mosanya, J., (2013): Socio-demographic and clinical correlates of subjective quality of life among Nigerian outpatients with schizophrenia. Psychiatry research, 209(3), 320325.

-Aish, M., (2013): Quality of Life Among Schizophrenic Patients in Gaza Governorates. Quality of Life Among Schizophrenic Patients in Gaza Governorates.

-Amr, M., El-Mogy, A., \& El-Masry, R., (2013): Adherence in Egyptian Patients with Schizophrenia: The Role of Insight, Medication Beliefs and Spirituality=. The Arab Journal of Psychiatry, 44(473), 1-18.

-Arraras, J., Ibañez, B., Basterra, I., Pereda, N., Martin, M., \& Iribarren, S., (2018): Determinants of Quality of Life in Spanish outpatients with schizophrenia spectrum disorders. The European Journal of Psychiatry, 32(3), 113-121.

-Atadokht, A., Ebrahimzadeh, S., \& Mikaeeli, N., (2019): The Effectiveness of Humor Skills Training on Positive and Negative Symptoms of Chronic Schizophrenia Spectrum Journal of Holistic Nursing and Midwifery, 29(1), 15-21scale (PANSS) for schizophrenia. Schizophrenia bulletin, 13(2), 261-276 specifictechniques.Routledg.

- Caqueo-Urízar, A., Urzúa, A., Mena-Chamorro, P., Fond, G., \& Boyer, L., (2020): Adherence to Antipsychotic Medication and Quality of Life in Latin-American Patients Diagnosed with Schizophrenia. Patient preference and adherence.

- Chandra, I., Kumar, K., Reddy, M., \& Reddy, C., (2014): Attitudes toward medication and reasons for non-compliance in patients with schizophrenia. Indian journal of psychological medicine, 36(3), 294. 
- Chaudhari, B., Saldanha, D., Kadiani, A., \& Shahani, R., (2017): Evaluation of treatment adherence in outpatients with schizophrenia. Industrial psychiatry journal, 26(2), 215.

-De Araújo, A., de Araújo Dantas, D., Do Nascimento, G., Ribeiro, S., Chaves, K., de Lima Silva, V., \& de Medeiros, C., (2014): Quality of life in patients with schizophrenia: the impact of socio-economic factors and adverse effects of atypical antipsychotics drugs. Psychiatric Quarterly, 85(3), 357-367.

Desalegn, D., Girma, S., \& Abdeta, T., (2020): Quality of life and its association with psychiatric symptoms and socio-demographic characteristics among people with schizophrenia: A hospitalbased cross-sectional study. Plos one, 15(2), e0229514.

-Ebrahem, S., \& Alam, F., (2016): Effectiveness of Psychiatric Nursing Intervention on Adherence to Medications and Quality of Life of Schizophrenic Patients. American Journal of Nursing Science, 5(6), 232-239.

-Effiong, J., \& Umoh, K., (2015): Medication non adherence in schizophrenia: Prevalenceand correlates among outpatients in a tertiary healthcare facility in Uyo, South-South Nigeria. Clin Med Diagn, 5(6), 107-113.

-El-Azzab, S., \& Abu-Salem, E., (2018): Effective strategies for nurses empowering the life quality and antipsychotic adherence of patients with schizophrenia. Journal of Nursing Education and Practice, 8(10).

-Elegbede, V., Obadeji, A., Adebowale, T., \& Oluwole, L., (2019): Comparative assessment of quality of life of patients with schizophrenia attending a community psychiatric center and a psychiatric hospital. Ghana Medical Journal, 53(2), 92-99.

-Endriyani, L., Chien, C., Huang, X., \& Chieh-Yu, L., (2019): The influence of adherence to antipsychotics medication on the quality of life among patients with schizophrenia in Indonesia. Perspectives in psychiatric care, 55(2), 147-152.

- Guedes de Pinho, L., Pereira, A., Chaves, C., (2018): Quality of life in schizophrenic patients: the influence of socio demographic and clinical characteristics and satisfaction with social support. TrendsPsychiatryPsychother.2018; 40 (3):202-209. Doi :10.1590/2237-6089-2017-0002 [PubMed] [CrossRef] [Google Scholar.

- Hayhurst, K., Drake, R., Massie, J., Dunn, G., Barnes, T., Jones, P., \& Lewis, S. (2014): Improved quality of life over one year is associated with improved adherence in patients with schizophrenia. European Psychiatry, 29(3), 191196.

-Karow, A., Wittmann, L., Schoettle, D., Schaefer, I., \& Lambert, M., (2014): The assessment of quality of life in clinical practice in patients with schizophrenia. Dialogues in clinical neuroscience, 16(2), 185.

-Kenfe, T., Girma, E., Negash, A., Tesfaye, M., and Dehning, S., (2013): Medication nonadherence among adult psychiatric outpatients in Jimma University Specialized Hospital,southwest Ethiopia. Ethiop J Health Sci.; 23(3): 227-236.

- Lacro, J., Dunn, L., Dolder, C., Leckband, S., \& Jeste, D. (2002): Prevalence of and risk factors for medication nonadherence in patients with schizophrenia: a comprehensive review of recent literature. The Journal of clinical psychiatry.

-Lim, M., \& Lee, J. (2018): Determinants of health-related quality of life in schizophrenia: Beyond the medical model. Frontiers in psychiatry, 9, 712 .

-Martin, L., Feig, C., Maksoudian, C., Wysong, K., \& Faasse, K. (2018): A perspective on non adherence to drug therapy: psychological barriers and strategies to overcome non adherence. Patient preference and adherence, 12, 1527. McIlroy, M., (2018): Medication Adherence Among Patients with Schizophrenia and Schizoaffective-Bipolar Type Disorder: A Clinical Education Approach to Improve Medication Compliance (Doctoral dissertation, Brandman University).

- Niolu, C., Bianciardi, E., Di Lorenzo, G., Marchetta, C., Barone, Y., Sterbini, N., \& Siracusano, A., (2015): Enhancing adherence, subjective well-being and quality of life in patients with schizophrenia: which role for long-acting risperidone? Therapeutic advances in psychopharmacology, 5(5), 278-288.

-Ogunnubi, O., Olagunju, A., Aina, O., \& Okubadejo, N., (2017): Medication adherence among Nigerians with schizophrenia: correlation between clinico-demographic factors and quality of life. Mental illness.

-Puschner, B., Born, A., Giessler, A., Giebler, A., Helm, H., Leese, M., Bindman JP, Gray RJ, Schene, A., Kikkert, M., Burti, L., Marrella, G., \& Becker, T. (2006): Adherence to medication and quality of life in people with schizophrenia: results of a European multicenter study. J. Nerv. Ment. Dis; 194 (10); 746-52.

-Sendt, K., Tracy, D., \& Bhattacharyya, S. (2015): A systematic review of factors influencing adherence to antipsychotic medication in schizophrenia-spectrum disorders. Psychiatry research, 225(1-2), 14-30. 
-Shehu, A., Garba, S., Anyebe, E., Tukur, M., \& Gomma, H., (2019): Adherence to drug treatment among schizophrenic patients in Jigawa State, Nigeria. Annals of African Medical Research, 2(1).

-Sridhar, R., Kumar, V., \& Hemanth, C. (2017): ESTIMATION OF TREATMENT COMPLIANCE IN SCHIZOPHRENIA-RESEARCH. life, 1, 2 ..

- Tan, X., Seow, E., Abdin, E., Verma, S., Sim, K., Chong, S., \& Subramaniam, M., (2019): Subjective quality of life among patients with schizophrenia spectrum disorder and patients with major depressive disorder. BMC psychiatry, 19(1), 267.

-Thompson, K., Kulkarni, J., Sergejew, A., (2000): Reliability and validity of a new Medication Adherence Rating Scale (MARS) for the psychoses. Schizophrenia Res. 2000; 42:241-7.

- Whiteford, H., Ferrari, A., Degenhardt, L., Feigin, V., \& Vos, T. (2015): The global burden of mental, neurological and substance use disorders, an analysis from the Global Burden of Disease Study 2010, PloS one, 10(2), e0116820 www.mirixa.com/uploads/pdfs/CHTMedAdhrWp. $\mathrm{p}(3-1-2021) 10 \mathrm{Am}$.

-World Health organization Quality of life group, (1998): the world health organization quality of life assessment (WHOQOL): Development and general psychometricproperties. Soc .sci.Med.46 (12) pp.15691585.retrievedfromwww.Psycholog .hku.hk\....docs thewhoqolgroup $\backslash 171$.

-Xiang, Y., Weng, Y., Leung, C., Tang, W., \& Ungvari, G., (2008): Subjective quality of life in outpatients with schizophrenia in Hong Kong and Beijing: relationship to socio-demographic and clinical factors. Quality of Life Research, 17(1), 27-36.

- Yin, Z., Li, J., Zhang, Y., Ren, A., Von Meneen, K., \& Huang, L., (2017): Functional brain network analysis of schizophrenic patients with positive and negative syndrome based on mutual information of EEG time series. Biomedical Signal Processing and Control, 31, 331-338

-Zipursky, R. (2014): Why are the outcomes in patients with schizophrenia so poor? J Clin Psychiatry. 2014; 75(2): 20-24. PMid: 24919167. https://doi.org/10.4088/JCP.13065su1.05. (3-12021)10Am. 